\title{
The enduring field: Exploring researcher emotions in covert research with antagonistic organisations
}

\author{
Heather Maguire $^{1}$ (D) | Andrew McCartan ${ }^{2}$ | Catherine Jean Nash ${ }^{1}$ | Kath Browne
}

${ }^{1}$ Geography and Tourism Studies, Brock University, St. Catharines, ON, Canada

${ }^{2}$ Department of Geography, Maynooth

University, Maynooth, Ireland

\section{Correspondence}

Heather Maguire

Email: hmaguire@brocku.ca

\section{Funding information}

Social Sciences and Humanities Research Council of Canada, Grant/Award Number: 435-2015-0071
This paper explores the emotional dimensions of doing covert research with antagonistic organisations. Drawing on the experiences of three researchers who identify as lesbian, gay, and LGBT ally, who covertly attended public and semipublic conferences and events organised by groups with heteroactivist positionings over two years, we consider the multiple, nuanced and complex emotional dimensions of being "behind enemy lines" (Jansson, 2010). We argue for greater consideration of the emotional spaces covert research creates, as in our case a "closet" space was produced which suppressed our sexualities or allyship. Furthermore, we argue that the process of doing covert research is one that both precedes and exceeds being in the field, and as such, we need to pay attention to researcher emotion as a process that begins long before we step into the field and continues long after we leave.

\section{K E Y W O R D S}

covert research, covert self, emotion, heteroactivism, lesbian, gay, bisexual and trans, positionality

\section{1 | INTRODUCTION}

Going undercover within antagonistic groups has long been a method used by activists and academics looking to understand and/or expose their inner workings, and in contemporary times is a prevalent choice of LGBT activists. For instance, during the Australian same-sex marriage campaign in 2017, the online LGBT news outlet Pink News sent undercover journalists to events organised by oppositional group Coalition for Marriage to report on the strategies of the "No" campaign. Within the academy, some of the authors of this paper have been undertaking covert participant observation since 2015, seeking to understand how anti-LGBT equalities discourses operate in Canada, the UK and Australia, places where these equalities have been "won," and to trace the growing resistance to the rights of LGBT people (Browne \& Nash, 2014; Nash \& Browne, 2015). Three members of our research team, Kath Browne, Andrew McCartan and Heather Maguire (who identify as lesbian, gay and LGBT ally respectively), have gone undercover, attending evangelical and anti-LGBT Christian group conferences, joining anti-feminist and anti-LGBT, "pro-family" organisations, participating in right-wing think tank and political party conventions, and various anti-LGBT rallies, talks and protests in Canada, Ireland, Wales and England. Our Research Ethics Board (REB) approved the research and required we observe only in public or semi-public places. While the REB provided pragmatic guidelines to ensure the ethical treatment and well-being of the research participants, there was no consideration of the well-being of the researchers (see TCPS2, 2014).

In this paper, we explore the tremendous emotional strain of doing covert research with those whose views are antithetical to our own and we consider the messy and often deeply unsettling emotional aspects of doing covert research as LGBT people and allies going undercover with heteroactivist organisations. We position our discussion within geographical 
scholarship that reinforces the material significance of researcher emotion in the constitution of the "field" and the resulting knowledge (Bondi, 2005; Catungal, 2017; Drake \& Harvey, 2014; Widdowfield, 2000). In the specific case of covert research, scholarship has focused primarily on the emotional well-being of research participants, who are often positioned as marginal, vulnerable populations (Arditti et al., 2010; Blee, 1998; Brotsky \& Giles, 2007). This scholarship does not consider the emotional well-being of the researcher, especially when engaging with antagonistic organisations, and in this paper we seek to address this gap.

Methodologically, we draw on our collective but independent experiences of doing covert research over a two-year period as recorded in our fieldnotes and researcher debriefing interviews. Prior to doing any covert research, the team agreed that fieldnotes should attend to the emotional dimensions of the work as part of the data-generation process (Drake \& Harvey, 2014; Finlay, 2002; Hubbard et al., 2001). In addition, during a research team meeting in 2016 we audio-recorded an afternoon debriefing session in which the two research assistants were interviewed about their undercover experiences, which was transcribed. Together, this provided rich, experiential data for our analysis.

We begin with a review of the literature on researcher emotions during fieldwork, followed by a consideration of the specificities of doing covert research. We then explore three moments in the process of doing covert research - the before, during and after moments of going undercover. Through this analysis, we argue for greater consideration of the emotional spaces covert research creates, as in our case such research produced "closet space" where power relations ensured the suppression of our sexualities or allyship. These emotional spaces are significant because they magnify the already-difficult terrain of doing covert research, including managing fieldwork relations and maintaining the "covert self" (Calvey, 2008; see also Chong, 2008). Second, we argue that more attention needs to be given to the emotional strain of covert research on the researcher, as a process that both precedes and exceeds the field. Covert research is a valuable tool, but better preparing researchers for the unique stresses and strains of doing undercover work, along with the potential for a much longer duration than anticipated, can enhance the data-generation process and interpretations thereof. In other words, if researchers are more aware of these issues in advance, they can better plan/prepare for them. We conclude with a reflection on the relational dynamics that reconstitute fieldwork spaces, and our place and practices within them.

\section{2 | EMOTIONS, FIELDWORK AND COVERT SPACES}

Emerging from a recognition that qualitative researchers experience research "both intellectually and emotionally" (Gilbert, 2001, p. 9), emotions have "come out of the closet" and a robust body of literature examines the role of emotions in doing fieldwork (Blee, 1998, p. 381; see also Bondi, 2005; Davidson et al., 2016; Jansson, 2010; Widdowfield, 2000). We understand emotions to be those internal feelings which are constituted by and within social relations that respond to and influence our actions in the field (Arditti et al., 2010; Bondi, 2005; Reger, 2001). This work highlights how our emotions are implicated in the research process, including recognising that our positioning and political beliefs play an important role in the relationship-building work inherent in qualitative work (e.g., Bondi, 2005). As Horton (2008) argues, we must give a full account of how our positionality matters, not only in terms of our questions and interpretations, but also in how we relate to others and our preconceived notions, without "navel-gazing"; that is, analyses of researcher emotion must be diligent, purposeful and resist self-indulgence (see also Widdowfield, 2000). Such studies can help "unburden" the researcher when studying emotionally difficult situations, including prisons (Arditti et al., 2010; Drake \& Harvey, 2014), homelessness (Cloke et al., 2000) and poverty, among others (Widdowfield, 2000).

These matters can be experienced more acutely when engaging with groups whose interests, values and beliefs do not align with those of the researcher (Chong, 2008; Jansson, 2010). Drake and Harvey (2014) discuss how, when working in the "extreme" environment of prison, researchers engage in impression management and "role strain" as they performed particular identities as prison researchers (see also Hammersley \& Atkinson, 1995). In our case, our "extreme" environment was particularly personal, as the groups we study are morally and vocally opposed to our very selves, friends and families. Jansson (2010, p. 20), in exploring his own positionality and emotional responses when studying a U.S.-based far-right group, found his emotional responses to this extreme environment to be no tidy ordeal; instead it played out as a battleground between his "head" and his "gut" as he wrestled with the knowledge that these were human beings, yet their beliefs were so opposed to his own. In our situations, we identify as either LGBT or ally, some of us with children and partners, and we engaged with groups who are opposed to same-sex marriage, have publicly declared same-sex parenting to be child abuse, and see acceptance of LGBT people as being a "slippery slope" to other kinds of threats to society, including pedophilia and bestiality. Thus, these oppositional views are very personal, and our REB approval (and the nature of the covert research itself) precluded us from responding, or even calling these views into question. 
Covert research, conducted without disclosing to research participants that they are being studied, involves embodying deception to an extent that the strain of maintaining the deception may become damaging to the researcher (Homan, 1980; Spicker, 2011). Researchers conceal their identities as they embed themselves in organisations or groups by "purporting to play some other role" (Vinten, 1994, p. 33; see also Gephart, 2004; Roulet et al., 2017). This concealment adds another dimension to "role strain," as rather than maintaining neutrality, researchers must "play along" so as to fit in (Drake \& Harvey, 2014). To play this other role, researchers construct what Calvey (2008) calls the "covert self." Creating a covert self is part of the "emotionally demanding" work of displaying "the relevant body and cultural capital and interaction rituals to pass" in the field (Calvey, 2008, p. 911). Less widely discussed is how taking on this role sometimes requires the concealment of other aspects of identity beyond that of being a researcher. As the heteroactivist groups we observe are conservative, right-wing aligned, anti-LGBT groups with political agendas that resist accepted public discourses of equality and inclusion, we also needed to conceal our identities as lesbian, gay and LGBT allies. While emotions may be out of the closet within the discipline, our research requires us to temporarily put ourselves back in the closet, leading to additional emotional stress. The covert self comes at the emotional costs of self-repression, along with the struggle to conform to conflicting values (Chong, 2008; Jansson, 2010). It is crucial for covert researchers to more openly discuss the range of emotional responses to fieldwork, including giving more thought to those that might be considered inappropriate or wrong (Chong, 2008).

To join this discussion as geographers, we seek to understand the relationship of the covert self and its emotional baggage with the specific spaces in which it manifests. Although spaces in a physical sense do not produce emotions, people socially construct space to give it meaning that produces emotions (Cylwik, 2001). From their work with incarcerated participants, Arditti et al. (2010) recognise that certain spaces can be associated with intense emotional pain. Further, Blee (1998) contends that social movements also have an emotional landscape to them, wherein emotions play a key role in constructing collective identities, motivating activism and creating a sense of affinity. Heteroactivists are connected by a desire to return society to heteronormative ideals that are associated with a negative emotional response to LGBT recognition. Their emotions are embedded in the spaces of their events; participants are expected to share an affinity. For successful covert observation, we needed to be seen as similarly emotionally functioning (Beatty, 2005). As LGBT people and allies in those spaces, we must also embody these expected emotions to keep our cover. If hiding our emotions and identities puts us back in the closet, then this means the field becomes not only our research space but also a closet space.

We found the metaphor of the "closet" an apt one for framing our experiences. The closet, as the "defining structure of gay oppression" (Sedgwick, 1990, p. 71), is a spatial metaphor that describes the "denial, concealment, erasure, or ignorance" of LGBT people in a society that "dictates heterosexuality is the only way to be" (Brown, 2000, p. 1). Brown argues that the closet materialises in empirical contexts significant to the performance of sexuality. The concealment of our sexualities and allyship is a performance of the closet that mediates the power of oppression (Brown, 2000). Although we were choosing to hide these parts of ourselves to remain covert, the power relations in the field meant that this choice was already made for us. When researching antagonistic participants, fear levels out the hierarchical distinction between the researcher and research subject, where outside of the research setting the subject is the oppressor and the researcher is the oppressed (Blee, 1998; Jansson, 2010). Our vulnerability was not known to our participants, but it was still there waiting to be taken advantage of if our cover was revealed. Our encounters in covert spaces were experienced in distinct phases, before, during and after, and we explore the emotional dimensions of these phases in what follows (Brotsky \& Giles, 2007; Taylor \& Bogdan, 1984).

\section{3 | BEFORE: PREPARING FOR COVERT RESEARCH WITH ANTAGONISTIC GROUPS}

We each experienced preparing for covert research differently, based on our positionality. For Andrew and Heather, doing covert research was paid employment and, as such, they were concerned about impressing their supervisors in addition to experiencing anxieties about being covert. They felt the desire to gain experience, perhaps publish and secure future work. At the same time, Andrew's position as a gay man would place him in hostile spaces where his identity was deemed offensive. Heather, an LGBT ally who would easily pass in the field, felt anxious about occupying spaces where she would be read as supportive of heteroactivists. Arguably, Kath's position as a full professor meant that she did not face the stresses of paid employment, but she is nevertheless deeply involved in seeing the project succeed, and so prepared to endure spaces of animosity that directly attacked her family so as to gain valuable data. There is very little guidance for researchers conducting covert research on how to plan covert identities (Bain \& Nash, 2006; Walters \& Godbold, 2014). We found 
ourselves focusing on our "identity," "back story" and appearance. We used our real names, in part due to having to use our credit cards to pay for event registrations, and also because, in stressful situations, it is easier to have identities align as closely to the truth as possible.

We modified our appearances by attempting to look conservative through changing our clothing and being conscious of our hairstyles and body language. For Andrew and Kath, this became a process of hiding what they assumed would be indications of their lesbian and gay identities - retreating back into the closet, including removing nail polish and piercings (Andrew), and toning down hairstyles. Kath was "worried about my hair [...] it is, in my boss's terms, 'too funky'!" Later, while attending the event, Kath noticed women with short hair and a man with purple hair also in attendance, making her wonder if she was overthinking her appearance.

Although we were willing to alter some aspects of our appearance, part of the complexity comes from realising that there were some things we were unwilling to change. For example, a rainbow bracelet worn by Kath as a symbol of love for her children was not something she was willing to part with. The induction phase involved making many difficult decisions where we experienced deep conflict between "the head and the gut" (Jansson, 2010). These particular decisions, made prior to entering the field, led to discomfort in the field, where Kath was unable to roll up her sleeves in the hot room because she had to hide the bracelet.

We also developed backstories, so that we could safely engage in conversation. The best strategy, we learned, was to keep our backstories as close to the truth as possible. We omitted details such as working at a university ${ }^{1}$ and planned on using our families to help us look acceptably family-friendly and conservative. We wanted people to make assumptions about who we were, while not outright lying. At one point, Andrew "borrowed" his best friend and framed her as his girlfriend. Likewise, Heather knew from her online research that organisations appreciated "family values" and she planned on mentioning that she had children to legitimise her presence.

As we prepared, we questioned our presentation of self and tried to mould ourselves into something we were not. Thus, the "role strain" associated with researching in "extreme" situations began much earlier than we had expected. Altering our appearance and creating backstories so as to blend in, while trying not to outright lie, was deeply worrying, not only because of the pressures to "pass" in the field, but also because these organisations directly oppose who we are and what we stand for. Emotions do not begin in the field; they are part of the preparation and play a role in everyday lives leading up to entering covert research spaces.

\section{4 | DURING: PERFORMING IN THE CLOSET}

Once in the field, we found ourselves occupying "closet space" that forced us to not only pass in the field, but repress our identities so as to appear similarly emotionally functioning (Beatty, 2005; Brown, 2000). We felt conflicting emotions and experienced moments that were, at best, uncomfortable and, at worst, traumatic and damaging. No matter how much we prepared intellectually, there was no way to fully anticipate the emotional work ahead of us (Jansson, 2010). Attending an event, large or small, means that to some extent one must participate to maintain cover. Sometimes, this meant laughing at jokes made at the expense of the LGBT community, or expressing disgust at LGBT people when those around us did. Andrew felt that acting "normal" was not enough; he had to put on a performance:

I guess you have to be looking around you, and if everyone's laughing you should laugh. [...] Me not reacting might not be that big of a deal but it seems like it is because you're very much aware that people might be looking at you. [...] You feel that you have to put on a performance.

When considering the embodied experience of overt participant observation, researchers sometimes need to give an outward bodily display that conflicts with their true feelings by not showing any emotion whatsoever (Dickson-Swift et al., 2009). However, for covert participant observation, we felt required to actually perform emotions in opposition to how we felt. Chong identifies this as a "quandary of conformity" as the researcher struggles with "the emotional costs of self-repression arising from the researcher's fundamental value conflicts with the group" (2008, p. 369). Although not insurmountable, each of us experienced this quandary differently. For Heather, it led to feelings of frustration and anger:

There were these moments when I just got plain angry [...] very quickly it devolved into this talk about how society has all gone to hell in a handbasket now gay people can get married [...] and I'm quoting what's said 
in the room here but pretty soon they're going to allow people to have sex with animals [...] but I was like devastated, I was angry [...] because they are talking about people that I know and love and work with ... I took it very personally.

At some points in the process, we remained silent and present so as to ensure the project was not exposed and for selfprotection. By quietly being in attendance and allowing the events to run uninterrupted, coupled with having to make overt displays of support, we felt complicit.

Kath, who is married with three small children, had an experience that was particularly traumatising because the event that she attended completely dismissed the legitimacy of her family, framing her parenting as "child abuse." The enormous emotional strain of being in the room with people who actively wanted to deny her family's existence became overwhelming, leaving her on the verge of tears. The traumatising experience of hearing attacks against our families, but not being able to respond, reinforced that no matter how much attention we paid to making our covert selves seem like the others at the event, we would never share affinity with them.

Scholars have identified a "guilt clause" from the sustained deception in which "the paradox was getting close to them without them getting close to [you]" (Calvey, 2008, p. 911). Andrew discussed how "nice" people were to him, offering him a flat should he ever be in London. However, knowing that these groups actively opposed his identity, he said it felt "weird":

Seeing how nice [they are], you move away from demonizing them ..., but it's still hard to think about them as good people, so then you start to feel bad. [T] hey're just doing what they think is best and they are doing it ... out of love, they don't hate anyone, it's love for God. But they are telling you that you are a bad person [...] You start to get really told that you're the enemy.

Andrew's conflicted emotions demonstrate just how difficult it is to occupy this closet space as a covert researcher who is LGBT at an anti-LGBT event, where his covert self is being treated warmly and his real self is being attacked.

The assault on Kath's family denied the "guilt paradox" altogether. She wrote in her fieldnotes:

These are not my people [...] I don't want to engage with people, not because I might be found out, although that is possible, but also because I don't want to connect, to empathise, to share myself in any way.

Rather than struggling with a drive towards getting close to her participants while not allowing them to get close to her, Kath wanted to disconnect entirely. Kath took time out during the break to connect with the Principal Investigator, Catherine Nash, to help refocus her efforts and motivations, thus enabling her to return for the afternoon sessions. While this did not assuage her feelings, it did provide an opportunity to refocus her intellectual project, and mitigate feelings of isolation, a significant emotional cost of doing "sensitive" research (Johnson \& Clarke, 2003). Indeed, each of us used breaks in programming to connect with friends, the research team and our families, in an effort to reduce feelings of isolation.

The emotional toll also took unexpected turns. At Kath's conference, parents spoke of their anxieties as their child expressed a desire to transition to a boy, and how little control they felt over the process. The mother argued, "we love our child" and this resonated deeply with Kath, as she felt unexpected empathy and connection:

When I heard this story, I found it hard not to empathise with the parents, especially if the positions were reversed, if my children were being brought up as section 28 came into being. What must loss of control, loss parental rights to choose and loss of your imagining of your child feel like? [...] How would I feel about a child who rejected their same-sex family as a moral abomination and I was told to support them, to not challenge them and indeed to allow them 'to grow up to be the woman that god wants her to be'?

These complexities highlight the ways in which emotional work undertaken in the field rarely follows linear narratives. The impacts of covert research on the individuals and groups we are dealing with in terms of their privacy is of course central. However, as Drozdzewski and Dominey-Howes point out, researchers "rarely spend time thinking about the outcome of that research on our own emotional wellbeing" $(2015$, p. 17). The practices of engaging in the field ask for us to make decisions that would otherwise run counter to ourselves, and in turn require us to engage emotionally with ideas, groups and individuals we would otherwise avoid. This is not familiar territory, as social research is often focused on those with 
whom we identify, empathise with and/or seek to support. Yet it can lead to unexpected insights, including possibilities of connections.

\section{5 | AFTERWARDS: THE ENDURING FIELD}

As soon as practicably possible on leaving the field, we were tasked with writing our notes. Writing up fieldnotes can be therapeutic, as they provide an opportunity to "unburden" and to process the researcher's experiences and emotions (Arditti et al., 2010; Drake \& Harvey, 2014; see also Finlay, 2002; Lofland \& Lofland, 2006). We reflected on our observations, made connections to other experiences and processed our emotions. Andrew said he felt relief about being able to reflect on his experiences without having to maintain his façade:

So [you] won't be holding back as much ... so like it does seem like it's a very useful thing. And you do feel excited when you're typing up your notes that you've got something good to write about.

Generating data through fieldnote writing is a key reflexive tool and an important part of the emotional dimensions of doing covert work, where researchers have an opportunity to reflect on what their covert selves have witnessed (Bergman \& Wettergren, 2015; Blee, 1998; Finlay, 2002).

However, we found afterwards that the field and its closeted spaces stretched out, a concern that has yet to be explored in the covert literature. One of the implications of using our real names is that we are conscious of our online presences. Organisations have our personal contact information and home addresses. Recently, Heather received a phone call from one of the "pro-family" organisations that she had joined. Taken off-guard, Heather was unable to don her "covert self" in time, and the emotions from the field quickly returned. Moreover, she has an online presence that can be read as being "friends" with these organisations. Her positionality as a newly graduated $\mathrm{PhD}$ means that she is very aware of her online presence, as she tries to gain employment. She worries about what might happen if she is Googled by a potential employer and what assumptions would they make based on her fake social networks (she does not have a "real" Facebook page to counter any of these assumptions).

Andrew, on the other hand, wonders what might happen if "friends" made at events might search him online and discover his real social media accounts or come across articles related to his LGBT activism. Stepping into the field (and into the closet) the first time, there was little concern that people would take the trouble to seek out more information about us. However, with each event we attended, we developed relationships which increased potential for exposure. Andrew's worry was that his identity would be discovered, and he would be "outed" at a future event - either as a researcher, a gay man or perhaps both.

Kath's experience is different, as she seeks to balance the need for covertness as researcher with the need to publish findings. Whereas usually academics seek to publish their research as quickly as possible while it is timely and "cutting edge," for Kath, doing this might endanger future covert research. Some organisations pay close attention to funding bodies, and they publish research agendas, professors' names and even seek to "out" research assistants. Kath worries about being "found out" when the research becomes public and online attacks that may permeate into "real" spaces. Covert and real selves cannot be easily separated and the emotional toll of doing covert research with antagonistic organisations extends into these "afterwards" moments.

\section{6 | CONCLUSION}

In this paper, we argued that the emotional dimensions of doing covert research with organisations whose values and beliefs are antithetical to our own produces "closet" space, where concealing our identities intensifies the strain of being in the field, and that this both precedes and exceeds the field itself. This highlights how we must attend to not simply the fieldwork itself, but also the before and after moments. This "stretched out" field is important, not only because it provides opportunity for thoughtful reflection on the extended periods of fieldwork activity, but also because it can produce a "closet space" which serves to intensify our experiences.

Researchers have called for examinations of researcher emotion so as to better understand data and the research process (Drake \& Harvey, 2014; Finlay, 2002; Widdowfield, 2000). What we have learned here is that there is a delicate balance between data generation and researcher stress, particularly in antagonistic situations. Researchers must balance the pain of 
doing this kind of research with its benefits. It is not simply a matter of avoiding difficult or painful situations, but rather learning how to manage those emotions so as to gain further knowledge and insights. In addition, there are unanticipated emotional moments along the way that we must pay attention to, including feeling sympathy or connection, which reminds us of our ethical responsibilities in the field (Calvey, 2008; Jansson, 2010).

Finally, not enough attention has been paid to the emotional impacts of doing covert research, or in preparing researchers to navigate their covert selves. This necessitates further critical thinking around covert researcher subjectivities, practices and engagements, to better understand the work put in by researchers. This will not only inform methodological and ethics discussions, it will also enrich the knowledge produced and the potentials for new knowledges.

\section{ACKNOWLEDGEMENTS}

The authors would like to thank the two anonymous reviewers for their helpful and insightful comments. This research was supported by a Social Sciences and Humanities Research Council of Canada grant (2015-2019).

\section{ENDNOTE}

${ }^{1}$ This decision was made because universities have become a target for many right-wing activists. At one talk, Jordan Peterson, a tenured professor at the University of Toronto, referred to universities as "snake pits" of leftist activities. Working at a university would therefore arouse suspicion, we feared.

\section{ORCID}

Heather Maguire iD http://orcid.org/0000-0002-0246-7638

\section{REFERENCES}

Arditti, J. A., Joest, K. S., Lambert-Shute, J., \& Walker, L. (2010). The role of emotions in fieldwork: A self-study of family research in a corrections setting. The Qualitative Report, 15, 1387-1414.

Bain, A., \& Nash, C. J. (2006). Undressing the researcher: Feminism, embodiment and sexuality at a queer bathhouse event. Area, $38,99-106$. https://doi.org/10.1111/j.1475-4762.2006.00663.x

Beatty, A. (2005). Emotions in the field: What are we talking about? Journal of the Royal Anthropological Institute, 11, 17-37. https://doi.org/ 10.1111/j.1467-9655.2005.00224.x

Bergman Blix, S., \& Wettergren, A. (2015). The emotional labour of gaining and maintaining access to the field. Qualitative Research, 15, 688704. https://doi.org/10.1177/1468794114561348

Blee, K. M. (1998). White-knuckle research: Emotional dynamics in fieldwork with racist activists. Qualitative Sociology, 21, 381-399. https:// doi.org/10.1023/A:1023328309725

Bondi, L. (2005). The place of emotions in research: From partitioning emotion and reason to the emotional dynamics of research relationships. In J. Davidson, L. Bondi, \& M. Smith (Eds.), Emotional geographies (pp. 231-246). Aldershot, UK: Ashgate.

Brotsky, S. R., \& Giles, D. (2007). Inside the 'pro-ana' community: A covert online participant observation. Eating Disorders, 15, 93-109. https://doi.org/10.1080/10640260701190600

Brown, M. P. (2000). Closet space: Geographies of metaphor from the body to the globe. London, UK: Routledge.

Browne, K., \& Nash, C. J. (2014). Resisting LGBT rights where "we have won": Canada and Great Britain. Journal of Human Rights, 13, $322-336$.

Calvey, D. (2008). The art and politics of covert research: Doing situated ethics in the field. Sociology, 42, 905-918. https://doi.org/10.1177/ 0038038508094569

Catungal, J. P. (2017). Feeling bodies of knowledge: Situating knowledge production through felt embeddedness. Tijdschrift Voor Economische en Sociale Geografie, 108, 289-301. https://doi.org/10.1111/tesg.12229

Chong, K. H. (2008). Coping with conflict, confronting resistance: Fieldwork emotions and identity management in a South Korean evangelical community. Qualitative Sociology, 31, 369-390. https://doi.org/10.1007/s11133-008-9114-0

Cloke, P., Cook, P., Cursons, J., Milbourne, P., \& Widdowfield, R. (2000). Ethics, reflexivity and research: Encounters with homeless people. Ethics, Place \& Environment, 3, 133-154. https://doi.org/10.1080/713665889

Cylwik, H. (2001). Notes from the field: Emotions of place in the production and interpretation of text. International Journal of Social Research Methodology, 4, 243-250. https://doi.org/10.1080/13645570110057924

Davidson, J., Bondi, L., \& Smith, M. (2016). Emotional geographies. London, UK: Routledge. 
Dickson-Swift, V., James, E. L., Kippen, S., \& Liamputtong, P. (2009). Researching sensitive topics: Qualitative research as emotion work. Qualitative Research, 9, 61-79. https://doi.org/10.1177/1468794108098031

Drake, D. H., \& Harvey, J. (2014). Performing the role of ethnographer: Processing and managing the emotional dimensions of prison research. International Journal of Social Research Methodology, 17, 489-501. https://doi.org/10.1080/13645579.2013.769702

Drozdzewski, D., \& Dominey-Howes, D. (2015). Research and trauma: Understanding the impact of traumatic content and places on the researcher. Emotion, Space and Society, 17, 17-21. https://doi.org/10.1016/j.emospa.2015.09.001

Finlay, L. (2002). 'Outing' the researcher: The provenance, process, and practice of reflexivity. Qualitative Health Research, 12, 531-545. https://doi.org/10.1177/104973202129120052

Gephart, R. P. (2004). Qualitative research and the Academy of Management Journal. Academy of Management Journal, 47, 454-462. https:// doi.org/10.5465/amj.2004.14438580

Gilbert, K. R. (2001). The emotional nature of qualitative research. London, UK: CRC.

Hammersley, M., \& Atkinson, P. (1995). Ethnography: Principles in practice. London, UK: Routledge.

Homan, R. (1980). The ethics of covert methods. British Journal of Sociology, 31, 46-59. https://doi.org/10.2307/590062

Horton, J. (2008). A 'sense of failure'? Everydayness and research ethics. Children's Geographies, 6, 363-383. https://doi.org/10.1080/ 14733280802338064

Hubbard, G., Backett-Milburn, K., \& Klemmer, D. (2001). Working with emotion: Issues for the researcher in fieldwork and teamwork. International Journal of Social Research Methodology, 4, 119-137. https://doi.org/10.1080/13645570116992

Jansson, D. (2010). The head vs. the gut: Emotions, positionality, and the challenges of fieldwork with a Southern nationalist movement. Geoforum, 41, 19-22. https://doi.org/10.1016/j.geoforum.2009.10.013

Johnson, B., \& Clarke, J. M. (2003). Collecting sensitive data: The impact on researchers. Qualitative Health Research, 13, 421-434. https://doi. org/10.1177/1049732302250340

Lofland, J., \& Lofland, L. H. (2006). Analyzing social settings. Belmont, CA: Wadsworth Publishing Company.

Nash, C. J., \& Browne, K. (2015). Best for society? Transnational opposition to sexual and gender equalities in Canada and Great Britain. Gender, Place \& Culture, 22, 561-577.

Reger, J. (2001). Emotions, objectivity and voice: An analysis of a 'failed' participant observation. Women's Studies International Forum, 24, 605-616. https://doi.org/10.1016/S0277-5395(01)00190-X

Roulet, T. J., Gill, M. J., Stenger, S., \& Gill, D. J. (2017). Reconsidering the value of covert research. Organizational Research Methods, 20, 487-517. https://doi.org/10.1177/1094428117698745

Sedgwick, E. K. (1990). Epistemology of the closet. Berkeley, CA: University of California Publishers.

Spicker, P. (2011). Ethical covert research. Sociology, 45, 118-133. https://doi.org/10.1177/0038038510387195

Taylor, S. J., \& Bogdan, R. (1984). Introduction to qualitative research methods: The search for meaning. New York, NY: Wiley.

TCPS2 (2014). Ethical conduct for research involving humans. Retrieved from http://www.pre.ethics.gc.ca/pdf/eng/tcps2-2014/TCPS_2_FINAL_ Web.pdf

Vinten, G. (1994). Participant observation: A model for organizational investigation? Journal of Managerial Psychology, 92, 30-38. https://doi. org/10.1108/02683949410059299

Walters, S. R., \& Godbold, R. (2014). Someone is watching you: The ethics of covert observation to explore adult behaviour at children's sporting events. Journal of Bioethical Inquiry, 11, 531-537. https://doi.org/10.1007/s11673-014-9543-2

Widdowfield, R. (2000). The place of emotions in academic research. Area, 32, 199-208. https://doi.org/10.1111/j.1475-4762.2000.tb00130.x

How to cite this article: Maguire H, McCartan A, Nash CJ, Browne K. The enduring field: Exploring researcher emotions in covert research with antagonistic organisations. Area. 2019;51:299-306. https://doi.org/10.1111/ area.12464 